Research Article

\title{
A Constitutive Model for Overconsolidated Structured Soils Using Structural Variable
}

\author{
Wugang Li $\mathbb{D}^{1},{ }^{1}$ Wenhua Liu, ${ }^{1}$ Zhijia Xue ${ }^{D},{ }^{2}$ and Xiuli Sun ${ }^{1}$ \\ ${ }^{1}$ Jiangnan University, Wuxi 214122, China \\ ${ }^{2}$ Chang'an University, Xi'an 710064, China \\ Correspondence should be addressed to Zhijia Xue; xuegeneral@126.com
}

Received 22 February 2021; Revised 12 July 2021; Accepted 1 August 2021; Published 10 August 2021

Academic Editor: Chengwei Fei

Copyright (c) 2021 Wugang Li et al. This is an open access article distributed under the Creative Commons Attribution License, which permits unrestricted use, distribution, and reproduction in any medium, provided the original work is properly cited.

Due to the influence of soil structure, structured soils exhibit significantly different mechanical behavior compared to the reconstituted soils having the same material. In this work, a theoretical analysis focusing on the mechanical behavior of structured soils is presented. Based on the mechanical behavior of the structured soil, a newly defined variable structural index was used as a measurement of the integrity of soil structure based on the concept of intrinsic compression line of intact structured soils. Furthermore, a novel correlation for the variation in volume of structured soils is established using effective stress and newly defined structural index as the constitutive variables. The novel correlation provided interpretation about the mechanism of compression behavior of the structured soils. Afterwards, the proposed correlation for the variation in volume was extended to triaxial stress state in the framework of subloading surface to include the effect of overconsolidation. Comparisons between the predictions and experimental results validated the proposed constitutive model for structured soils.

\section{Introduction}

Generally, the natural soils possess a certain structure. The mechanical behavior of structured soils behaves differently from the reconstituted soils owing to the existence of soil structure between the particles. Based on the experimental data from reconstituted soils, a modified Cam-Clay (MCC) model [1] was established. However, the experimental data [2-6] from structured soils brought to light the limitations of the MCC model. Many projects in geotechnical engineering involved structured soils. The constitutive model excludes the mechanical behavior of structured soils, and its application to the design of geotechnical engineering will seriously impact the reliability of civil structure. Therefore, incorporating the mechanical behavior of structured soils into the constitutive model is particularly important.

Many studies have been conducted to study the mechanical behavior of structured soils, and significant progress has been achieved in this regard. Recently, the critical state theory was extended to illustrate the mechanical behavior of structured soils [7-12]. However, these constitutive models are established based on the conventional elastoplastic theory. According to the conventional elastoplastic theory, soils behave elastically if the applied stress is less than the yield stress. Therefore, the stress-strain relationship changes abruptly at the yield stress according to these constitutive models. The smoothness condition is violated in this case. Besides, Burland [13] pointed out that structured soils often exhibit irrecoverable deformation upon unloading and reloading even in overconsolidated state. According to the conventional elastoplastic theory, simulating the irrecoverable behavior upon unloading and reloading of structured soils is beyond the application of these models. Recently, unconventional elastoplasticity models were proposed for a better simulation of the mechanical behavior of soils. Yao et al. [14] established the relationships between the current yield surface, the reference yield surface, and the Hvorslev envelope to consider the influence of overconsolidation on the stress dilatancy and strain softening behavior of overconsolidated clays. Suebsuk et al. [15] extended the MSCC model [10] by bounding surface plasticity to describe the irrecoverable deformation 
of structured clays during unloading and repeated loading. Six new parameters were introduced into the model compared to the parent MCC model [1]. Xiao et al. [16] and Xiao et al. [17] proposed a constitutive model for overconsolidated clays in the framework of disturbed state concept [18]. It is worth pointing out that a smaller number of parameters in a model provide a significant advantage by making the model simple for practical use.

The key to constitutive model for structured soils is how to describe the impact of the soil structure on the mechanical behavior of structured soils. In this paper, a new variable is proposed as a measurement of the integrity of soil structure. Moreover, a new constitutive model for structured soils using the newly defined variable as a state variable is established in the current paper. The new constitutive model is capable of describing the effect of soil structure and overconsolidation.

\section{Volume Change Behavior of Structured Soils}

The soil structure controls the mechanical behavior of structured soils. Therefore, the mechanical behavior of soils needs to be investigated before establishing the constitutive model for structured soils. Anagnostopoulos et al. [19] conducted compression tests on Corinth Canal marl with high structure strength. The Corinth Canal marl mainly consists of $1.5-3 \%$ illite, $1.0-7.0 \%$ chlorite, and $73-75 \%$ calcite. The sand content is generally less than $12 \%$, whereas the silt-sized fraction lies within the range of $75-87 \%$. Furthermore, the clay-sized fraction lies within the range of 13-24\%. According to the unified soil classification system (USCS), the Corinth Canal marl is classified as a low plasticity clay or silt. Figure 1 shows the compression curve of the Corinth Canal marl. The yield stress of Corinth Canal marl is apparent. According to the experimental results, the soil is supposed to behave elastically before the stress reaches the yield stress. After the applied stress exceeds the yield stress, the compression index increases obviously due to the degradation of soil structure. When the structured soils are fully destructured due to the increased applied stress, the compression curve of structured soils coincides with the compression line of the reconstituted soils having the same material.

According to the experimental data, a common pattern of the compression behavior for the structured soils can be depicted in Figure 2. The soils are elastic before the soil structure breaks down. If the structure of the soils remains intact with the increase in applied stress, the compression curve of the structured soils will be represented by the dashed line as depicted in Figure 2. $\kappa^{\prime}$ is used to represent the slope of the dashed line as illustrated in Figure 2. In this case, the variation in the void ratio of the structured soils before the soil structure breaks down can be expressed by the following equation:

$$
d e=-\kappa^{\prime} \frac{d p^{\prime}}{p^{\prime}},
$$

where $p^{\prime}$ is the mean effective stress. The dashed line characterizes the compression behavior for the intact structured soils. It is defined as the intrinsic compression line of the structured soils (ISCL).

Soil structure is induced by the cementation between the soil particles and the arrangement of soil particles. The cementation between the soil particles often has a certain strength. Therefore, the soil structure enables structured soils to sustain a higher volume than the reconstituted soils having the same soil material under a given stress value. The soil structure begins to break down when the applied stress reaches the yield stress, which induces the increase in the plastic deformation. As a result, the compression index of structured soils increases with the degradation of soil structure. When the soil structure is fully destructured, the compression curve of structured soils coincides with the compression line of the reconstituted soils, as depicted in Figure 2. These results show that the normal compression line of reconstituted soils (NCL) and the intrinsic compression line of structured soils (ISCL) define the boundaries of the compression curves for structured soils.

An initially intact frictional structured soil sample is investigated to quantify the degradation of soil structure during compression. Three new parameters $e_{d}, e_{s}$, and $e_{I}$, defined as the distance between the ISCL and compression line for structured soils (SCL), the distance between the SCL and NCL, and the distance between the ISCL and NCL, respectively, are introduced (see Figure 2). Before the degradation of soil structure occurs, the variation in volume of structured soils behaves elastically. In this case, the value of $e_{d}$ is zero, and the value of $e_{s}$ equals the value of $e_{I}$. As the stress continues to increase, slippage at interparticles happens due to the degradation of soil structure. As a consequence, plastic deformation of structured soils starts to increase. In this case, the value of $e_{d}$ begins to increase, and the value of $e_{s} / e_{I}$ begins to decrease from unity. When the structure of the soil is fully destroyed, the structured soils change into reconstituted soils. As a result, the compression line of the structured soil coincides with that of the reconstituted soils. In this case, the value of $e_{d}$ equals the value of $e_{I}$, whereas the value of $e_{s} / e_{I}$ decreases to zero.

According to the above analysis, it can be seen that the values of $e_{d}, e_{s}$, and $e_{I}$ are related to the structural characteristics of soil. The value of $e_{d}$ is related with the degradation of the soil structure. The value of $e_{s}$ is related to the structural characteristics and describes the differences between the structured soils and the reconstituted soils having the same material. The parameter $e_{I}$ represents the structure characteristic of the intact structured soils. A normalized variable, structural index $\xi$, is suggested as a measurement of the integrity of the structure of soil, and is given by the following equation:

$$
\xi=\frac{e_{\mathrm{s}}}{e_{\mathrm{I}}}
$$

The value of $\xi$ decreases monotonously with the degeneration of the soil structure and varies from unity (intact structured soils) to zero (reconstituted soils). 


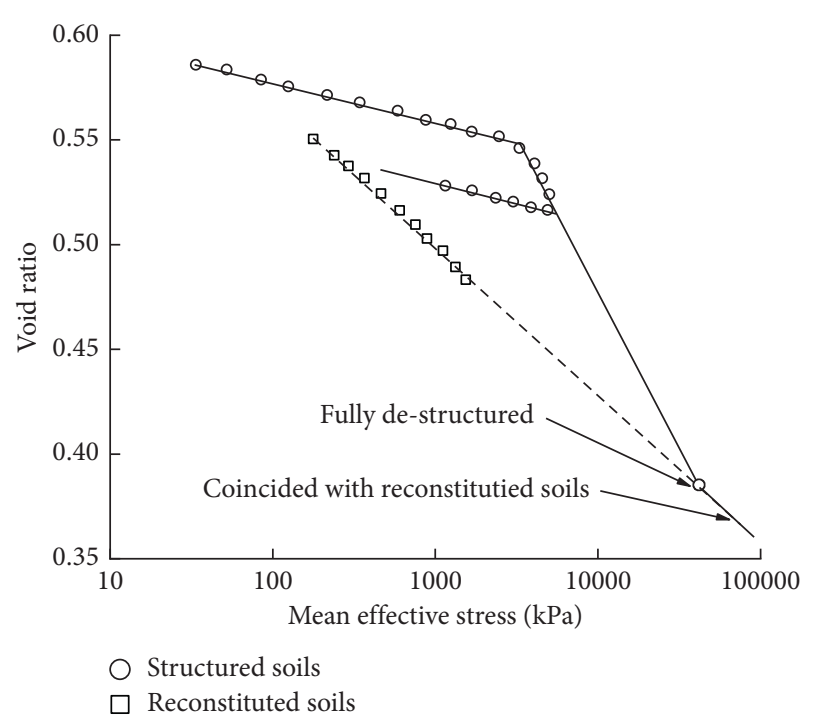

Figure 1: Compression line for Corinth canal marl [19].

A widely used correlation for the change of void ratio for reconstituted soils [1] is given by the following equation:

$$
e=e_{r}-\lambda \ln \left(\frac{p^{\prime}}{p_{r}^{\prime}}\right)
$$

where $e$ is the void ratio, $e_{r}$ is the void ratio at the reference state, $\lambda$ is the slope of the compression line for the reconstituted soils, and $p_{r}^{\prime}$ is the mean effective stress at a reference state. Based on the relationship between the compression curves of reconstituted soils and structured soils, the change in void ratio for structured soils is given by the following equation:

$$
e=e_{r}-\lambda \ln \left(\frac{p^{\prime}}{p_{r}^{\prime}}\right)+\xi e_{I}
$$

The value of $e_{I}$ is the distance between NCL and ISCL at the same stress as shown in Figure 2. Combining equations (1) and (3), the value of $e_{I}$ can be obtained as

$$
e_{I}=\left(\lambda-\kappa^{\prime}\right) \ln \frac{p^{\prime}}{p_{r}^{\prime}} .
$$

Combining equations (4) and (5), equation (6) is obtained, which can be used for the change of void ratio of structured soils.

$$
e=e_{r}-\left[(1-\xi) \lambda+\xi \kappa^{\prime}\right] \ln \left(\frac{p^{\prime}}{p_{r}^{\prime}}\right) .
$$

Equation (6) describes the volume change behavior for structured soils during compression. The increment of void ratio can be written as

$$
d e=-\left[(1-\xi) \lambda+\xi \kappa^{\prime}\right] \frac{d p^{\prime}}{p^{\prime}}+\left(\lambda-\kappa^{\prime}\right) \ln \left(\frac{p^{\prime}}{p_{r}^{\prime}}\right) d \xi
$$

It can be seen that the increment of void ratio of structured soils is induced by the change of mean effective stress and the degradation of soil structure, as depicted in Figure 3. The compression index for structured soils is given by the expression $\left[(1-\xi) \lambda+\xi \kappa^{\prime}\right]$, provided the structural index $\xi$ stays constant during compression. The value of the change in void ratio induced by the degradation of soil structure can be expressed using the expression $\left(\lambda-\kappa^{\prime}\right) \ln \left(p^{\prime} / p_{r}^{\prime}\right) d \xi$ and is higher than zero. Therefore, the apparent compression index of structured soils varies with the degradation of soil structure.

\section{Formulation of the Constitutive Model for Overconsolidated Structured Soils}

The total volumetric strain consists of the elastic strain and the plastic strain. Therefore, the total volumetric strain can be written as

$$
\varepsilon_{v}=\varepsilon_{v}^{e}+\varepsilon_{v}^{p},
$$

where $\varepsilon_{v}$ is the total volumetric strain. The superscripts $e$ and $p$ stand for elastic and plastic, respectively. According to the conventional elastoplastic theory, the elastic volumetric strain is given by

$$
\varepsilon_{v}^{e}=\frac{\kappa}{1+e_{r}} \ln \frac{p^{\prime}}{p_{r}^{\prime}}
$$

The total volumetric strain for structured strain can be obtained according to equation (6) and can be expressed as

$$
\varepsilon_{v}=\frac{\left[(1-\xi) \lambda+\xi \kappa^{\prime}\right]}{1+e_{r}} \ln \frac{p^{\prime}}{p_{r}^{\prime}} .
$$

The plastic strain of the structured soils is derived from equations (8)-(10), and can be expressed as

$$
\varepsilon_{v}^{p}=\varepsilon_{v}-\varepsilon_{v}^{e}=\left\{\frac{\left[(1-\xi) \lambda+\xi \kappa^{\prime}\right]}{1+e_{r}}-\frac{\kappa}{1+e_{r}}\right\} \ln \frac{p^{\prime}}{p_{r}^{\prime}} .
$$

The equivalent yield stress for structured soils defines the yield stress for reconstituted soils with the plastic volumetric strain and is denoted by $p_{c}^{\prime}$. The relationship between $p_{c}^{\prime}$ and $\varepsilon_{v}^{p}$ can be expressed using the following equation:

$$
\varepsilon_{v}^{p}=\frac{(\lambda-\kappa)}{1+e_{r}} \ln \frac{p_{c}^{\prime}}{p_{r}^{\prime}} .
$$

Combining equations (11) and (12), the yield stress for structured soils is obtained in terms of the equivalent yield stress as

$$
p^{\prime}=p_{r}^{\prime}\left(\frac{p_{c}^{\prime}}{p_{r}^{\prime}}\right)^{\left((\lambda-\kappa) /\left[(1-\xi) \lambda+\xi \kappa^{\prime}-\kappa\right]\right)} .
$$

Equation (13) indicates that the yield stress for structured soils is related to the structural index $\xi$. A numerical example is presented here to illustrate the change of equivalent yield stress $p_{c}^{\prime}$ with structural index under different yield stresses $p^{\prime}$ of structured soils. The values of material parameters $\lambda, \kappa$, and $\kappa^{\prime}$ for frictional structured soils are assumed to be $0.1,0.02$, and 0.02 , respectively. The simulation results are shown in Figure 4 . It is seen that the 
reduction of structural index $\xi$ induces an increase in the equivalent yield stress, which is due to the degradation of soil structure.

Modified Cam-Clay model [1] is applied in this study as an example of extending equation (11) to triaxial stress state. The yield surface of the structured soils is assumed to have the form given by

$$
f=\ln \frac{p^{\prime}}{p_{x}^{\prime}}+\ln \left(1+\frac{q^{2}}{M^{2} p^{\prime 2}}\right)=0
$$

where $M$ is the slope of the critical state line and assumed to have the same value as that of the reconstituted soils [20,21], $q$ is the deviator stress, and $p_{x}^{\prime}$ represents the size of yield surface of structured soils.

Combining equations (13) and (14), the yield surface for structured soils can be written as

$$
f=\ln \frac{p^{\prime}}{p_{r}^{\prime}}+\ln \left(1+\frac{q^{2}}{M^{2} p^{\prime 2}}\right)-\frac{1+e_{r}}{\left[(1-\xi) \lambda+\xi \kappa^{\prime}-\kappa\right]} \varepsilon_{v}^{p}=0 .
$$

Equation (15) implies that the structural index $\xi$ impacts the relationship between stress and strain for structured soils. Due to the limitation of conventional elastoplastic theory, equation (15) is unable to simulate the mechanical behavior of overconsolidated structured soils. The framework of subloading surface [21] implies the inclusion of the effect of overconsolidation of structured soils. Subloading surface is used to describe the effect of stress history and soil structure, as shown in Figure 5.

According to equation (15), the normal yield surface is given by

$$
f=\ln \frac{\bar{p}^{\prime}}{p_{r}^{\prime}}+\ln \left(1+\frac{\bar{q}^{2}}{M^{2} \bar{p}^{\prime}}\right)-\frac{1+e_{r}}{\left[(1-\xi) \lambda+\xi \kappa^{\prime}-\kappa\right]} \varepsilon_{v}^{p}=0 .
$$

Based on the similarity between the subloading surface and the normal yield surface, equations (17) and (18) are obtained.

$$
\begin{aligned}
& \frac{q}{\bar{q}}=\frac{p^{\prime}}{\bar{p}^{\prime}}=R, \\
& \frac{p^{\prime}}{\bar{p}^{\prime}}=\frac{p_{N}^{\prime}}{p_{X}^{\prime}} R,
\end{aligned}
$$

where $1 / R$ is the overconsolidation ratio. From equations (16)-(18), the yield surface for overconsolidated structured soils is given by

$$
f=\ln \frac{p^{\prime}}{p_{r}^{\prime}}+\ln \left(1+\frac{q^{2}}{M^{2} p^{\prime 2}}\right)-\ln R-\frac{1+e_{r}}{\left[(1-\xi) \lambda+\xi \kappa^{\prime}-\kappa\right]} \varepsilon_{v}^{p}=0 .
$$

With the development of $R$ during compression, the subloading surface moves towards the normal yield surface.
When the subloading surface coincides with the normal yield surface, the value of $R$ increases to unity. In this case, equation (19) degenerates into the normal yield surface for normal consolidated structured soils. According to the consistency correlation of $d f=0$, the following equation is obtained:

$$
d f=\frac{\partial f}{\partial \sigma_{i j}} d \sigma_{i j}+\frac{\partial f}{\partial R} d R+\frac{\partial f}{\partial \xi} d \xi+\frac{\partial f}{\partial \varepsilon_{v}^{p}} d \varepsilon_{v}^{p}=0 .
$$

The increment of plastic strain can be obtained according to the associated flow rule, as given by the following equation:

$$
d \varepsilon_{i j}^{p}=\Lambda \frac{\partial f}{\partial \sigma_{i j}} .
$$

where $\Lambda$ is the plastic multiplicator. The increment of stress can be obtained according to the generalized Hook's law, as given by

$$
d \sigma_{i j}=E_{i j k l} d \varepsilon_{k l}^{e}=E_{i j k l}\left(d \varepsilon_{k l}-\Lambda \frac{\partial f}{\partial \sigma_{k l}}\right),
$$

where $E_{i j k l}$ is the elasticity modulus. Substituting equations (21) and (22) into equation (20), the plastic multiplicator is obtained as follows:

$$
\Lambda=\frac{\partial f / \partial \sigma_{i j} \in E_{i j k l} d \varepsilon_{k l}+\partial f / \partial R d R+\partial f / \partial \xi d \xi}{\partial f / \partial \sigma_{i j} E_{i j k l}\left(\partial f / \partial \sigma_{k l}-\partial f / \partial \varepsilon_{v}^{p}\right) \partial f / \partial p^{\prime}} .
$$

It can be seen that the evolution rule for the state variable $R$ and $\xi$ needs to be determined before calculating the plastic multiplicator. The increment of $R$ is defined as a positive scalar function with regard to the plastic strain [22]. Therefore, the increment of $R$ is assumed to be represented by the following equation:

$$
d R=U(R)\left\|d \varepsilon_{i j}^{p}\right\|
$$

where $U(R)$ decreases with the increase in $R$ and fulfills the condition given by equations (25) and (26).

$$
\begin{gathered}
U(0)=\infty, \\
U(1)=0 .
\end{gathered}
$$

In this study, the evolution rule for $U(R)$ [23] is modified to include the influence of soil structure and is given by

$$
U(R)=-\frac{\alpha\left[(1-\xi) \lambda+\xi \kappa^{\prime}-\kappa\right]}{1+e_{\mathrm{r}}}\left(\frac{p^{\prime}}{p_{r}^{\prime}}\right)^{2} \ln R,
$$

where $\alpha$ is a positive material parameter.

The increment of plastic strain leads to the decrease of structural index $\xi$. Therefore, the structural index $\xi$ monotonically decreases with the increase in plastic strain (see equation (28)).

$$
\xi=\xi\left(\varepsilon_{i j}^{p}\right)
$$




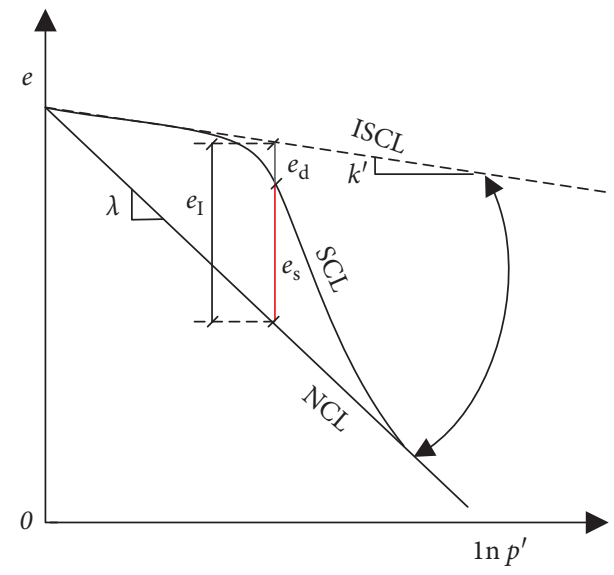

FIgURE 2: Compression line for structured soils.

According to the definition of structural index $\xi$, equation (28) fulfills the following conditions:

$$
\begin{aligned}
\xi(0) & =1, \\
\xi(\infty) & =0 .
\end{aligned}
$$

Destructuring is usually associated with plastic volumetric strain and plastic shear strain [24, 25]. Before giving the expression for structural index $\xi$, the following assumptions are made for the sake of simplicity. The damage to soil structure is continued, whereas the strength of mesoscopic elements of soil structure follows the Weibull distribution function [26]. A simple expression for the structural index $\xi$ is used in this paper, which is given by

$$
\xi=\exp \left[-\left(\frac{\sqrt{\left(\varepsilon_{v}^{p}\right)^{2}+\left(m_{d} \varepsilon_{d}^{p}\right)^{2}}}{\theta}\right)^{m}\right]
$$

where $m$ defines the rate of degradation of the soil structure, $m_{d}$ is a material parameter describing the influence of deviator strain on the degradation of soil structure, and $\theta$ represents the effect of the structural strength. According to equation (30), the evolution law of structural index $\xi$ is given by

$$
d \xi=-\frac{\xi m}{\theta^{m}}\left[\left(\varepsilon_{v}^{p}\right)^{2}+\left(m_{d} \varepsilon_{d}^{p}\right)^{2}\right]^{m / 2-1}\left(\varepsilon_{v}^{p} d \varepsilon_{v}^{p}+m_{d} \varepsilon_{d}^{p} d \varepsilon_{d}^{p}\right) .
$$

The mean effective stress for structured soils is assumed as $p_{0}^{\prime}$. The initial void ratio is $e_{0}$ as shown in Figure 6. The yield stress of the structured soils corresponds to the stress at Point B. The void ratio at Point B can be determined according to equation (6) and is given by

$$
e_{B}=e_{r}-\left[(1-\xi) \lambda+\xi \kappa^{\prime}\right] \ln \left(\frac{p^{\prime}}{p_{r}^{\prime}}\right) .
$$

Before the applied stress reaches the yield stress, only elastic deformation develops during the compression. Therefore, the void ratio of Point B can also be expressed using the following equation:

$$
e_{B}=e_{0}-\kappa \ln \frac{p^{\prime}}{p_{0}^{\prime}}
$$

Combining equations (32) and (33), the yield stress for structured soils is derived, as given by the following equation:

$$
p_{y}^{\prime}=\exp \left\{\frac{e_{r}+\left[(1-\xi) \lambda+\xi \kappa^{\prime}\right] \ln p_{r}^{\prime}-\kappa \ln p_{0}^{\prime}-e_{0}}{(1-\xi) \lambda+\xi \kappa^{\prime}-\kappa}\right\},
$$

where the subscript $y$ stands for yield stress. According to equations (18), the initial value for state variable $R$ can be expressed using the following equation:

$$
R_{0}=\frac{p_{y}^{\prime}}{p_{0}^{\prime}}=\frac{1}{p_{0}^{\prime}} \exp \left\{\frac{e_{\mathrm{r}}+\left[(1-\xi) \lambda+\xi \kappa^{\prime}\right] \ln p_{r}^{\prime}-\kappa \ln p_{0}^{\prime}-e_{0}}{(1-\xi) \lambda+\xi \kappa^{\prime}-\kappa}\right\} .
$$

\section{Performance of the Proposed Model}

Five parameters in the proposed model $(M, N, \lambda, \kappa$, and $\nu)$ are identical to those in the MCC model, and they are determined accordingly. The parameter $\alpha$ describes the evolution of the overconsolidation, whereas the parameters $m_{d}, m$, and $\theta$ describe the evolution of soil structure upon a given stress path. The value of parameters $m, \theta$, and $\alpha$ can be calibrated by fitting the isotropic compression curves of structured soil. The value of parameter $m_{d}$ can be determined by fitting the triaxial shearing results. Moreover, the parameter $\kappa^{\prime}$ represents the slope of the intrinsic compression line of the intact structured soils. It can be determined from the compression tests of structured soils. If no experimental data about the intrinsic compression line are available, the value of $\kappa^{\prime}$ can be assumed to be the same as $\kappa$ for simplicity.

4.1. Simulations of the Isotropic Compression Tests. The performance of the proposed model is assessed by a fictional structured soil. The values for the parameters $M, N, \lambda, \kappa, \nu, \alpha$, $m_{d}, m, \theta$, and $\kappa^{\prime}$ are assumed to be $1.1,3.0,0.2,0.02,0.25,0.5$, $1.0,1.4,0.1$, and 0.03 , respectively. The values of $p_{0}^{\prime}$ and $e_{0}$ at the initial state are $10 \mathrm{kPa}$ and 1.92 , respectively. The proposed model was illustrated by the simulations of isotropic compression tests in the first scenario. The loading path includes the following three steps as shown in Figure 7.

Step 1: the specimens under isotropic compression from $10(\mathrm{~A})$ to $10\left(\mathrm{~B}_{1}\right), 100\left(\mathrm{~B}_{2}\right), 200\left(\mathrm{~B}_{3}\right)$, and $400\left(\mathrm{~B}_{4}\right)$ $\mathrm{kPa}$, respectively $(\mathrm{A}-\mathrm{B})$

Step 2: the mean effective stress is decreased from 10 $\left(\mathrm{B}_{1}\right), 100\left(\mathrm{~B}_{2}\right), 200\left(\mathrm{~B}_{3}\right)$, and $400\left(\mathrm{~B}_{4}\right)$ to $10\left(\mathrm{C}_{1}, \mathrm{C}_{2}, \mathrm{C}_{3}\right.$, $\left.\mathrm{C}_{4}\right) \mathrm{kPa}(\mathrm{B}-\mathrm{C})$

Step 3: the mean effective stress is increased from 10 $\left(\mathrm{C}_{1}, \mathrm{C}_{2}, \mathrm{C}_{3}, \mathrm{C}_{4}\right) \mathrm{kPa}$ to a high value $(\mathrm{C}-\mathrm{E})$

The fictional specimens under a given stress path have different structural indices and overconsolidation ratios. The 


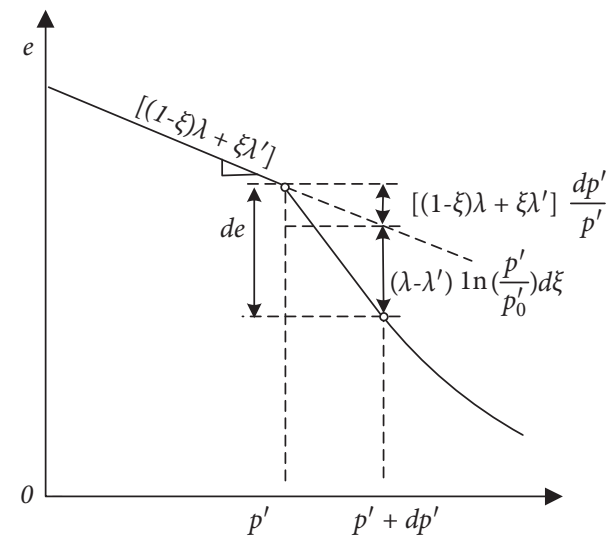

Figure 3: The volume change for structured soil.

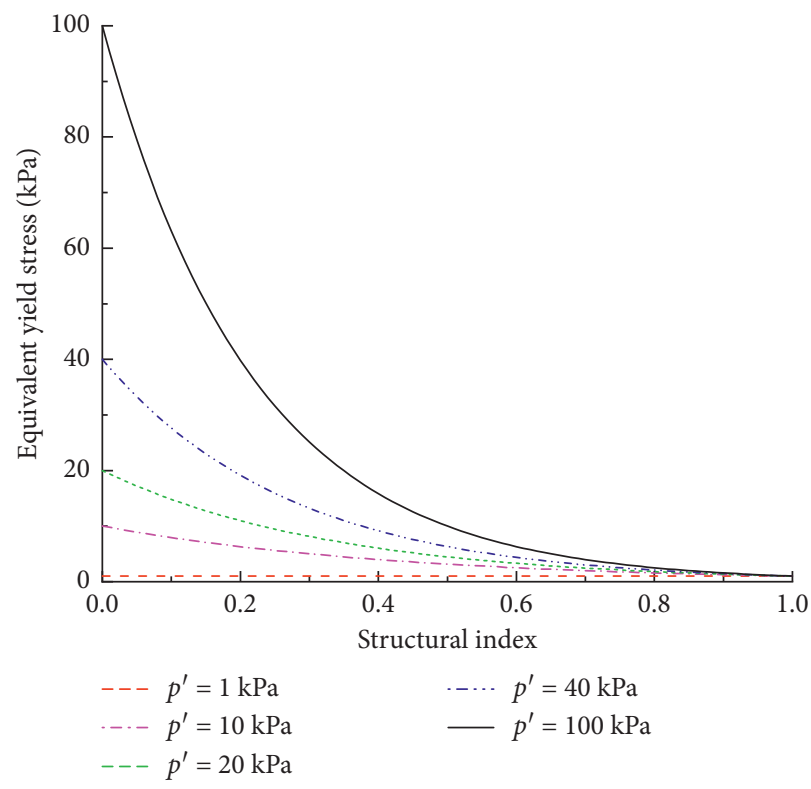

FIGURE 4: The relationships between the yield stress of structured soils and structured variable.

mean effective stress $p_{0}^{\prime}$ and void ratio $e_{0}$ at Point $\mathrm{A}$ are $10 \mathrm{kPa}$ and 1.92, respectively. The initial structural index at Point A can be calculated using equation (30), and the value is found to be 0.98. According to equations (6) and (9), the void ratio at Points $\mathrm{C}_{1}, \mathrm{C}_{2}, \mathrm{C}_{3}$, and $\mathrm{C}_{4}$ for stress path $\mathrm{A}-\mathrm{B}-\mathrm{C}$ can be calculated, and their values are found to be 1.92, 1.24, 1.07, and 0.92 , respectively. Figure 8 plots the predicted results for stress path $\mathrm{C}$-E. It can be seen that the simulated compression curves are nonlinear and smooth. The sample (C1) with a higher structural index $\left(\xi_{1}=0.98\right)$ exhibits lower compression index at the beginning of the compression process. With the increase of applied stress, the soil structure of sample (C1) breaks down suddenly and induces the compression index to a high value as the plastic strain continues to increase. When the structure of the soil is heavily destructured, the compression curves of structured soils get closer to the compression line of the reconstituted soils having the same material.
Due to the irrecoverable deformation upon stress path A-B-C, Samples C2, C3, and C4 show lower initial structural index at Point $\mathrm{C}$ compared to Sample $\mathrm{C} 1$ and, therefore, are in the overconsolidated state. Furthermore, the compression lines of the specimens are located below the normal compression line of the reconstituted soils. At the beginning of the compression process, Specimens C2, C3, and C4 exhibit lower compression indices. As the stress continues to increase, the compression curves of the structured soils cross the compression line of the reconstituted soils and exhibit higher void ratios than the reconstituted soils due to the influence of soil structure. With the increase in plastic strain, the state variable $R$ attains the value of unity. Meanwhile, the compression curves of Samples C2, C3, and C4 coincide with the compression curve of Sample C1. Finally, the compression lines of the structured soils converge to the compression line of the reconstituted soils when the soil structure is fully destructured as the plastic strain continues to increase. 


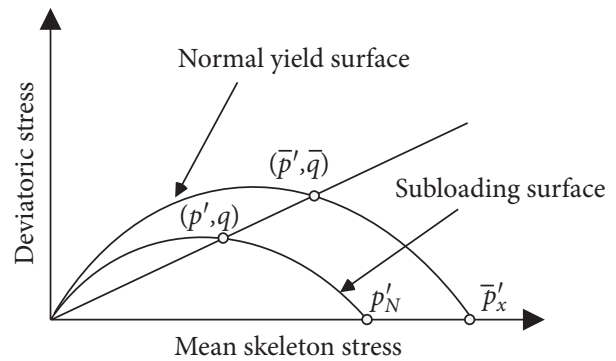

FIGURE 5: Extension of subloading concept to structured soils.

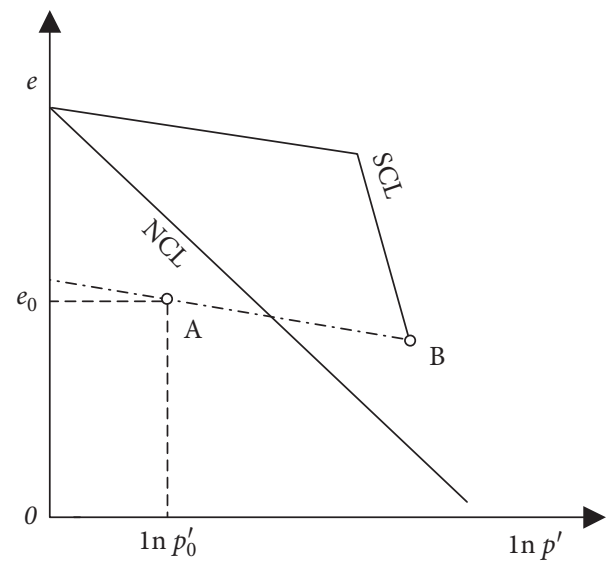

FIGURE 6: Yield stress for structured soil.

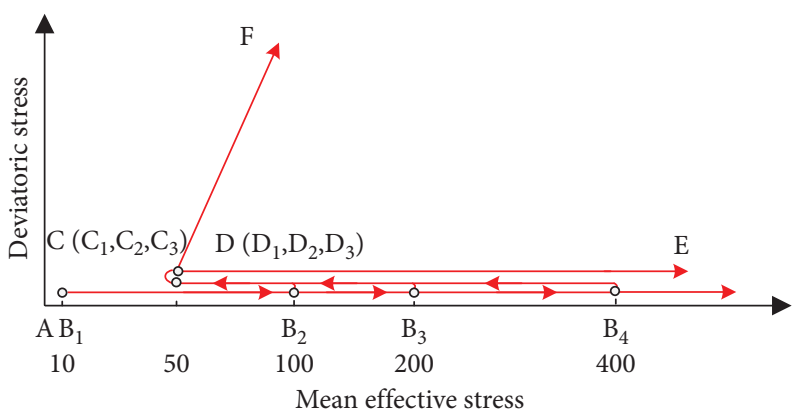

FIgURE 7: Stress paths for the fictional soils.

4.2. Simulations of Triaxial Compression Tests. The proposed model was illustrated by the simulations of triaxial compression tests in the second scenario. The loading path includes following two steps.

Step 4: the specimens under isotropic compression from $10\left(\mathrm{C}_{1}, \mathrm{C}_{2}, \mathrm{C}_{3}, \mathrm{C}_{4}\right) \mathrm{kPa}$ to $50\left(\mathrm{D}_{1}, \mathrm{D}_{2}, \mathrm{D}_{3}, \mathrm{D}_{4}\right) \mathrm{kPa}$ (C-D)

Step 5: the axial stress is increased from $50\left(D_{1}, D_{2}, D_{3}\right.$, $\left.\mathrm{D}_{4}\right) \mathrm{kPa}$ to a high value under constant lateral stress (D-F)

The numerical results for the fictional samples are presented in Figure 9. Relationships between the deviator stress and axial strain are presented in Figure 9(a). The structural index of Sample D1 is 0.328 , which means that most of the soil structure breaks down during the compression upon stress path $A_{1}-B_{1}-C_{1}-D_{1}$. The stress-strain relationship of Specimen D1 is strain hardening due to the degeneration of soil structure upon stress path A-B. The stress-strain relationships of Samples D2, D3, and D4 vary from strain hardening to strain softening with the increase of overconsolidation ratio. Besides, Samples D1, D2, D3, and D4 with different structural indices reach the same critical state. Figure 9(b) presents the relationships between the volumetric strain and axial strain. It is seen that the volume change behavior varies from contraction to swelling with the increase of overconsolidation ratio. According to the simulated results, the proposed constitutive model is capable of describing the basic mechanical behavior of the overconsolidated structured soils. 


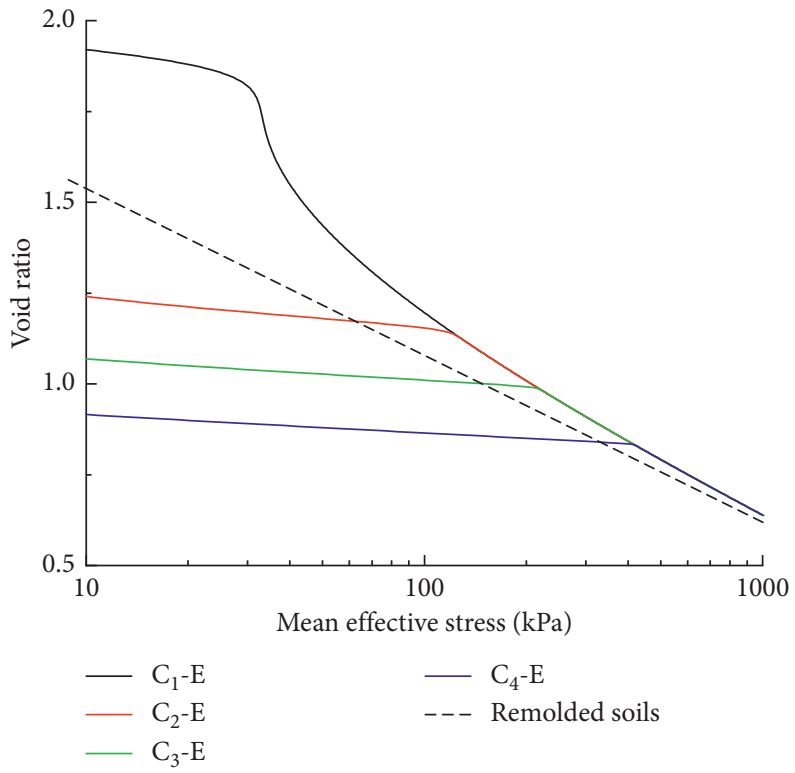

Figure 8: Compression curves for structured soils with different structural indexes.

\section{Comparisons of Model Predictions with Experimental Data}

In this section, the performance of the proposed model was evaluated by comparing the model predictions with the experimental data. The compression and shearing behaviors of different kinds of structured soils were considered. Based upon some previous studies, four different types of soils (Adachi et al. [27]; Anagnostopoulos et al. [19]; Balasubramanian and Hwang [28]; Smith et al. [29]) were used to validate the success of the proposed model in describing the compression behavior of structured soils. The Osaka clay (Adachi et al. [27]) is a soft sensitive clay. The clay deposits include a sand portion of a column structure. The Corinth marl is classified as a low plasticity clay as reported by Anagnostopoulos et al. [19] and exhibits brittle behavior and high stiffness due to the existence of structural bonding induced by the cementation between the individual particles. The Bangkok clay (Balasubramanian and Hwang [28]) and Bothkennar clay (Smith et al. [29]) are typical natural soft clays. The compression results were used to assess the capacity of the proposed model to describe the compression behavior of the structured soils. The model parameters for structured soils are listed in Table 1.

Figure 10 illustrates the experimental results and simulated isotropic compression behavior of Osaka clay (Adachi et al. [27]). It can be seen that the natural Osaka clay has a higher void ratio than the reconstituted Osaka clay under the same mean effective stress. The additional void maintained by soil structure decreased when the applied stress reached the yield stress due to the degradation of soil structure. Comparison between the experimental data and simulation indicates that the new model gives a reasonable prediction of the compression behavior of the structured soils. The comparisons between the measured and simulated compression behavior of Corinth marl (Anagnostopoulos et al.
[19]), Bangkok clay (Balasubramanian and Hwang [28]), and Bothkennar clay (Smith et al. [29]) are illustrated in Figures 11-13, respectively. It can be seen that the apparent higher compression of structured soils is captured by the proposed model. The comparison between the experimental data and model predictions indicates that the proposed model is capable of satisfactorily predicting the compression behavior of structured soils.

The influence of stress ratio on the compression curves of Leda clay was investigated by Walker and Raymond [30]. The experimental data were used to validate the proposed model. The compression index $\lambda$, stress ratio at critical state $M$, swelling index $\kappa$, and Poisson's ratio $v$ are $0.25,1.2,0.018$, and 0.25 , respectively. The value of $\kappa^{\prime}$ is assumed to be the same as that of $\kappa$. The value of $N$ at the reference state is 2.85 . Furthermore, the parameters $\theta, m, m_{\mathrm{d}}$, and $\alpha$ can be obtained by fitting the experimental data when stress ratio $q / p$ is equal to 1.0 , and their values are $0.4,1.03,0.004$, and 0.5 , respectively. The predicted results by the proposed model are presented in Figure 14. The degradation of soil structure is dependent on the magnitude of the current stress ratio according to equation (31). Therefore, the sample with higher stress ratio exhibited larger volume change during the compression due to the faster degeneration rate of the soil structure. The simulated results were consistent with the experimental data, as shown in Figure 14. The comparison also indicates that the proposed model satisfactorily reproduces the volume change behavior of the Leda clay.

Cotecchia [31] conducted a series of tests on the structured Pappadai clay. Experimental data are presented in Figures 15 and 16. The compression index $\lambda$, the stress ratio at the critical state $M$, the swelling index $\kappa$, and Poisson's ratio $v$ are found to be $0.206,1.0,0.019$, and 0.4 , respectively. The value of $\kappa^{\prime}$ is assumed to be the same as that of $\kappa$. The value of $N$ at the reference state is found to be 4.17 . The parameters $\theta, m$, and $\alpha$ are determined according to the 


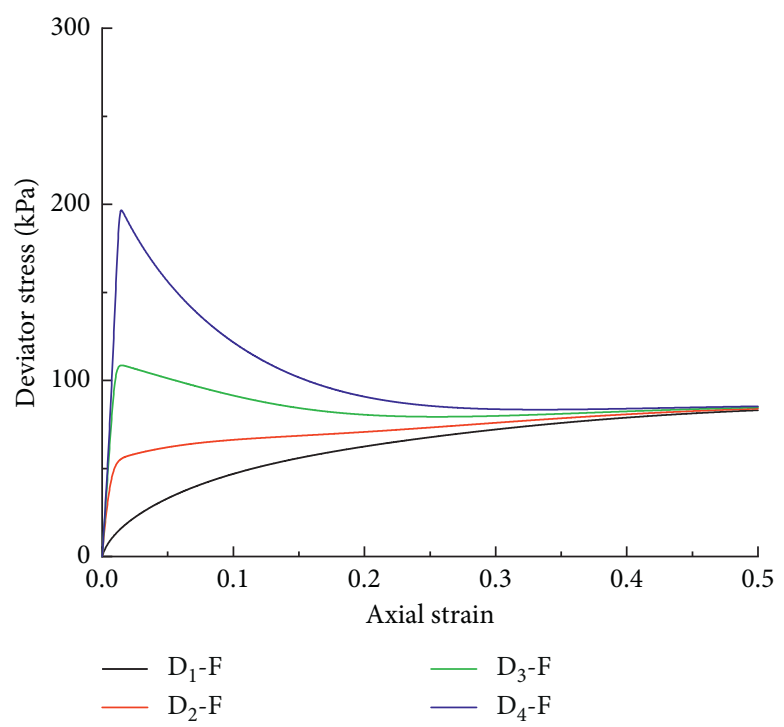

(a)

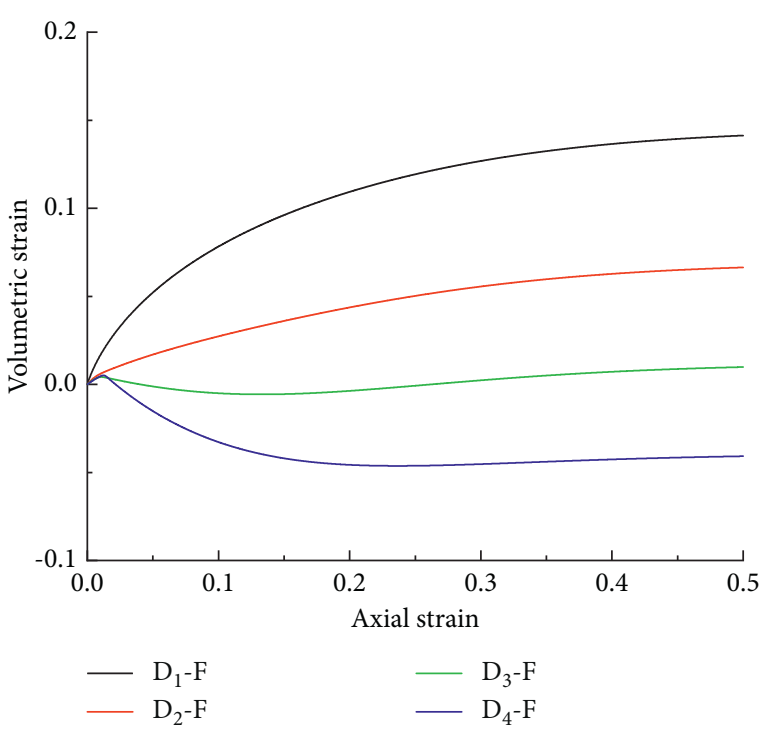

(b)

FIGURE 9: Mechanical behavior of structured soils with various structural indexes under constant lateral stress: (a) deviator stress-strain relationship; (b) volumetric strain-axial strain relationship.

TABLE 1: Soil model parameters for structured soils.

\begin{tabular}{lcccc}
\hline Parameters & $\begin{array}{c}\text { Osaka clay (test data } \\
\text { after Adachi et al. } \\
[27])\end{array}$ & $\begin{array}{c}\text { Corinth marl (test data after } \\
\text { Anagnostopoulos et al. [19]) }\end{array}$ & $\begin{array}{c}\text { Bangkok clay (test data after } \\
\text { Balasubramanian and Hwang [28]) }\end{array}$ & $\begin{array}{c}\text { Bothkennar clay (test data } \\
\text { after Smith et al. [29]) }\end{array}$ \\
\hline$\lambda$ & 0.19 & 0.04 & 0.4 & 0.26 \\
$M$ & 1.2 & 1.38 & 0.9 & 1.2 \\
$\kappa$ & 0.05 & 0.008 & 0.1 & 0.05 \\
$v$ & 0.25 & 0.25 & 0.25 & 0.25 \\
$\mathcal{K}^{\prime}$ & 0.012 & 0.008 & 0.135 & 0.02 \\
$\theta$ & 0.105 & 0.11 & 1.15 & 1.155 \\
$m$ & 0.95 & 1.1 & 1.0 & 1.0 \\
$\alpha$ & 1.0 & 1.0 & \\
\hline
\end{tabular}

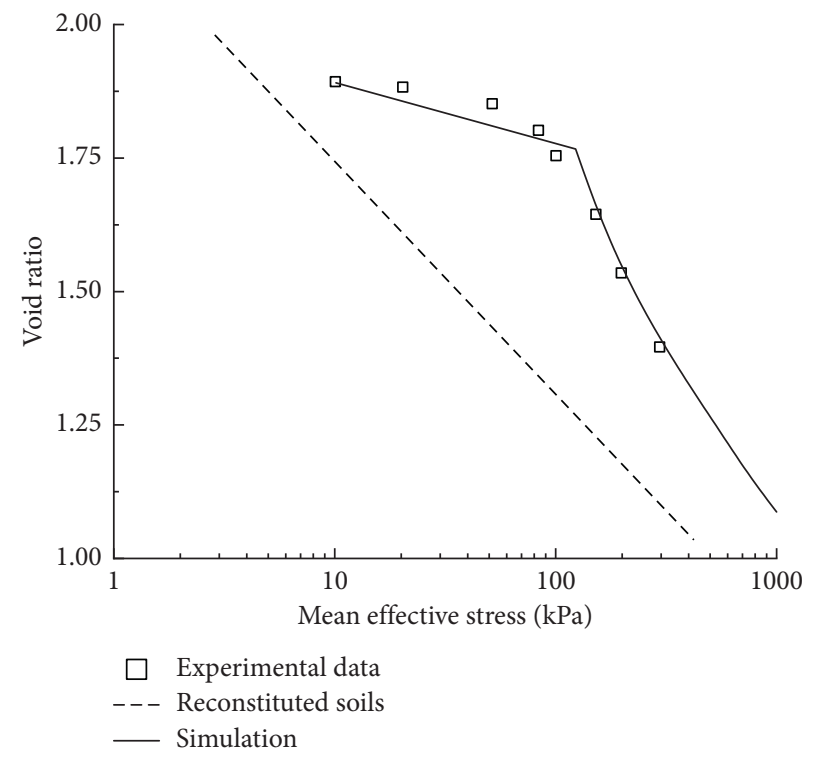

Figure 10: Experimental data and simulation of Osaka clay (test data after Adachi et al. [27]). 


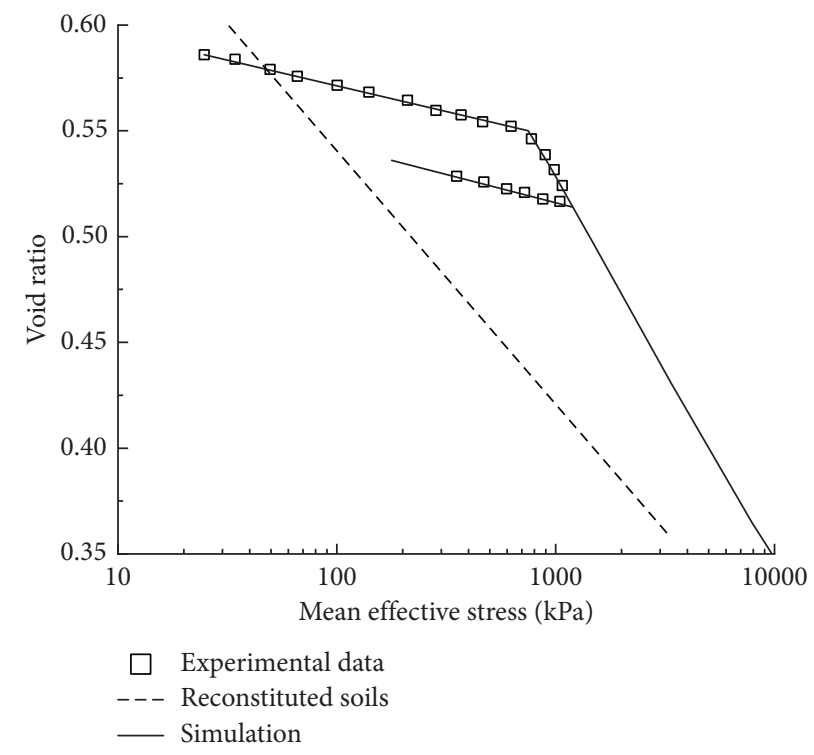

FIgURE 11: Experimental data and simulation of Corinth marl (test data after Anagnostopoulos et al. [19]).

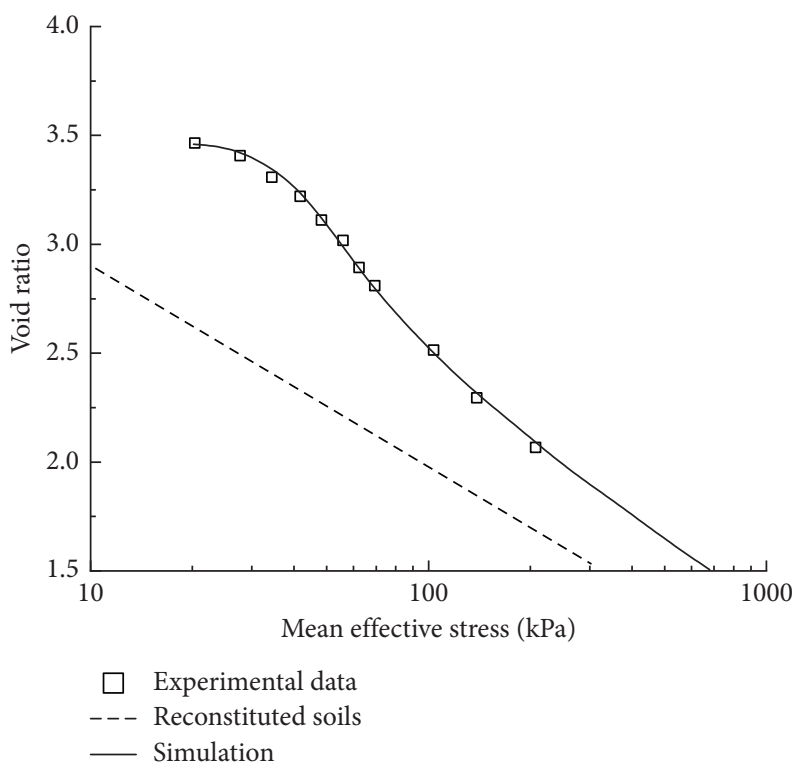

Figure 12: Experimental data and simulation of Bangkok clay (test data after Balasubramanian and Hwang [28]).

compression curve as shown in Figure 15. The values of $\theta, m$, and $\alpha$ are found to be $0.17,1.08$, and 0.02 , respectively. The parameter $m_{\mathrm{d}}$ is calibrated according to the experimental results of triaxial compression tests under $1500 \mathrm{kPa}$ lateral stress, and the value is found to be 0.5 . Specimens were isotropically compressed under 500,800 , and $1500 \mathrm{kPa}$ lateral stress, respectively, which resulted in overconsolidation ratios of $2.82,2.5$, and 1.34 , accordingly. The smooth stress-strain relationship is captured well by the proposed model as shown in Figure 16. The experimental data indicated that the specimens with low lateral stress exhibited peak strength and postpeak strain softening, whereas the sample with high lateral stress exhibited strain hardening due to the degradation of soil structure induced by the high lateral stress. It is seen that the model yields reasonable simulations about the triaxial compression behavior of the structured Pappadai clay at several different overconsolidation ratios.

Anagnostopoulos et al. [19] conducted triaxial compression tests on Corinth Canal marls to investigate the influence of soil structure. The specimens underwent isotropic compression to the mean effective stress values of 294, 903,1500 , and $4000 \mathrm{kPa}$ and, then, further compressed under constant lateral stress. The experimental data are 


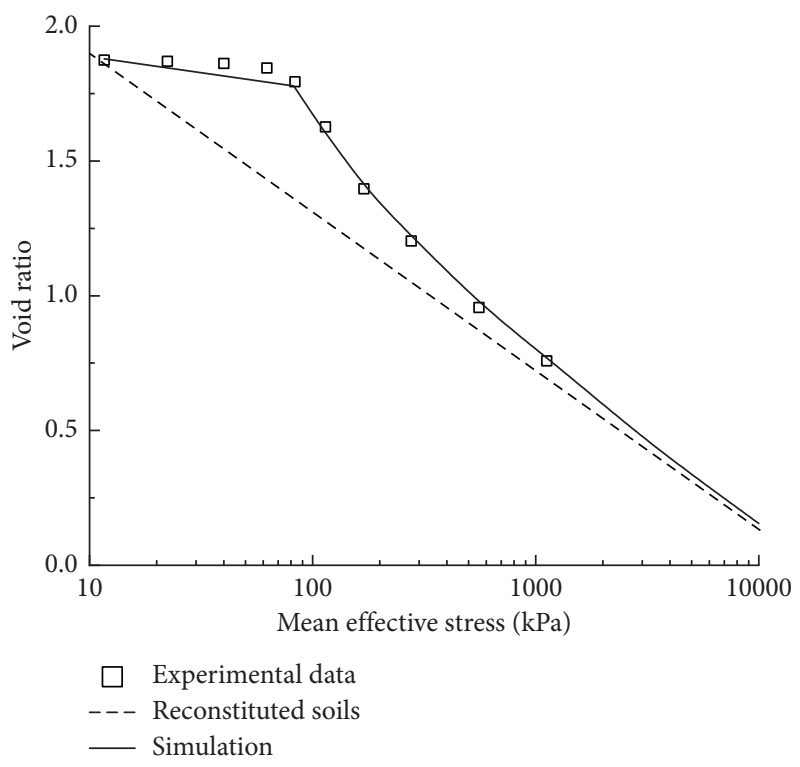

FIGURE 13: Experimental data and simulation of Bothkennar clay (test data after Smith et al. [29]).

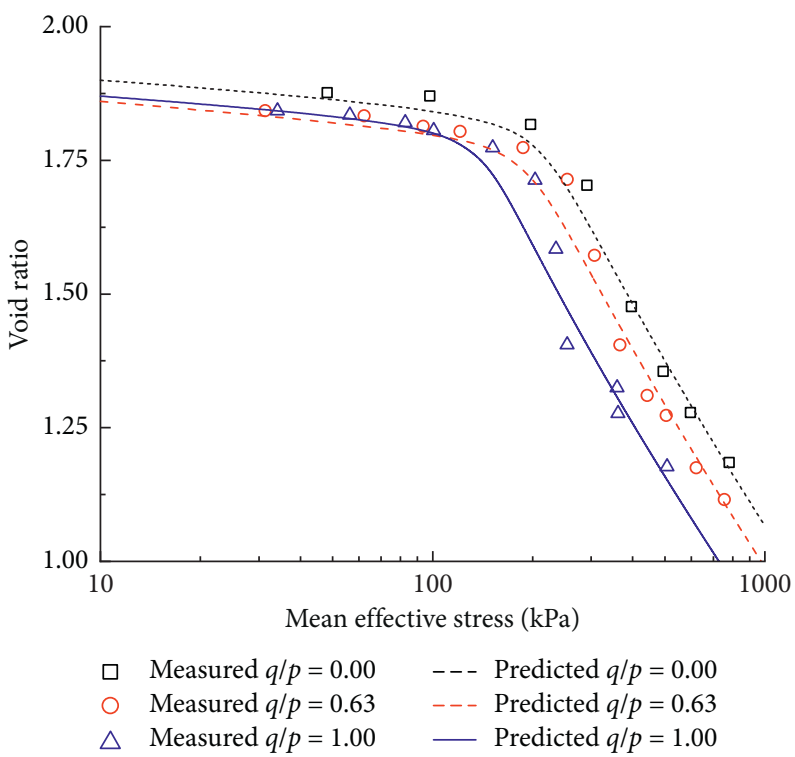

FiguRe 14: Comparisons between predictions and experimental results for Leda clay.

shown in Figure 17. The compression index $\lambda$, the slope of the critical state line $M$, the swelling index $\kappa$, and Poisson's ratio $v$ are found to be $0.04,1.32,0.008$, and 0.25 , respectively. The value of $\kappa^{\prime}$ is assumed to be the same as that of $\kappa$. The value of $N$ at the reference state is found to be 0.775 . The parameters $\theta, m, m_{d}$, and $\alpha$ are determined by the experimental data under $1500 \mathrm{kPa}$ lateral stress. The values of $\theta, m$, $m_{d}$, and $\alpha$ are found to be $0.1,1.1,0.2$, and 0.4 , respectively. Specimens were isotropically compressed under 298, 903, 1500 , and $4000 \mathrm{kPa}$ lateral stress, respectively, which resulted in overconsolidation ratios of $13.89,4.55,2.74$, and 1.17, accordingly. The stress-strain relationship is shown in
Figure 17(a). Again, the smooth stress-strain relationship is captured well by the proposed model. Because the soil structure was destroyed at high stress state, the sample with higher lateral stress exhibited strain hardening, whereas the sample with low lateral stress exhibited peak strength and postpeak strain softening. Figure 17(b) shows the change of volumetric strain with axial strain. The specimen with low lateral stress exhibited an increase and then a decrease in the volumetric strain with the increase in the axial strain. It can be seen that the basic mechanical behavior of the structured Corinth Canal marls is captured by the proposed model over a range of several different overconsolidation ratios. 


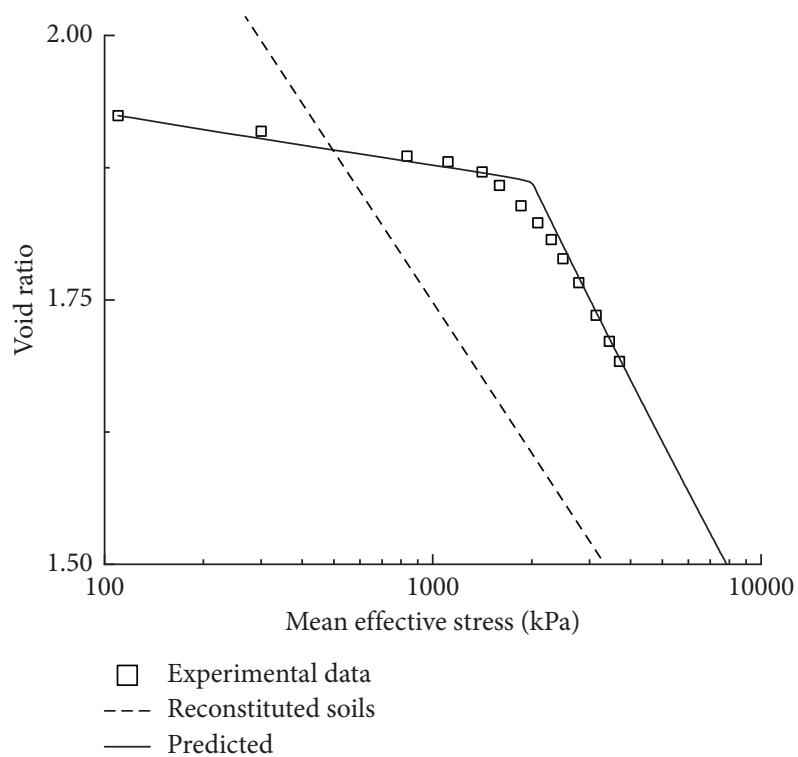

Figure 15: Comparisons of the simulations and experimental data for Pappadai clay.

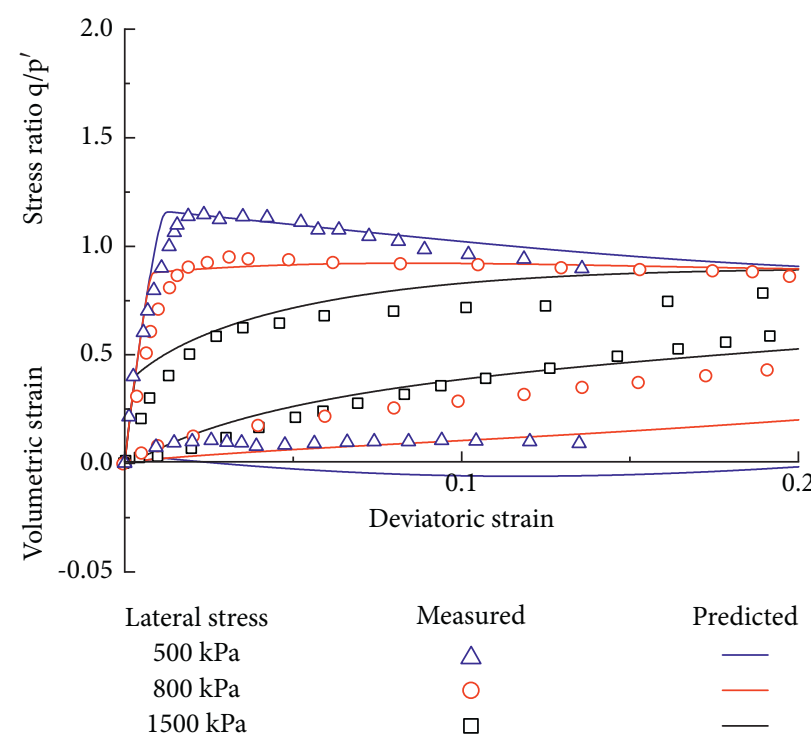

FIgURE 16: Comparisons of the predictions and experimental data for Pappadai clay under triaxial compression. 


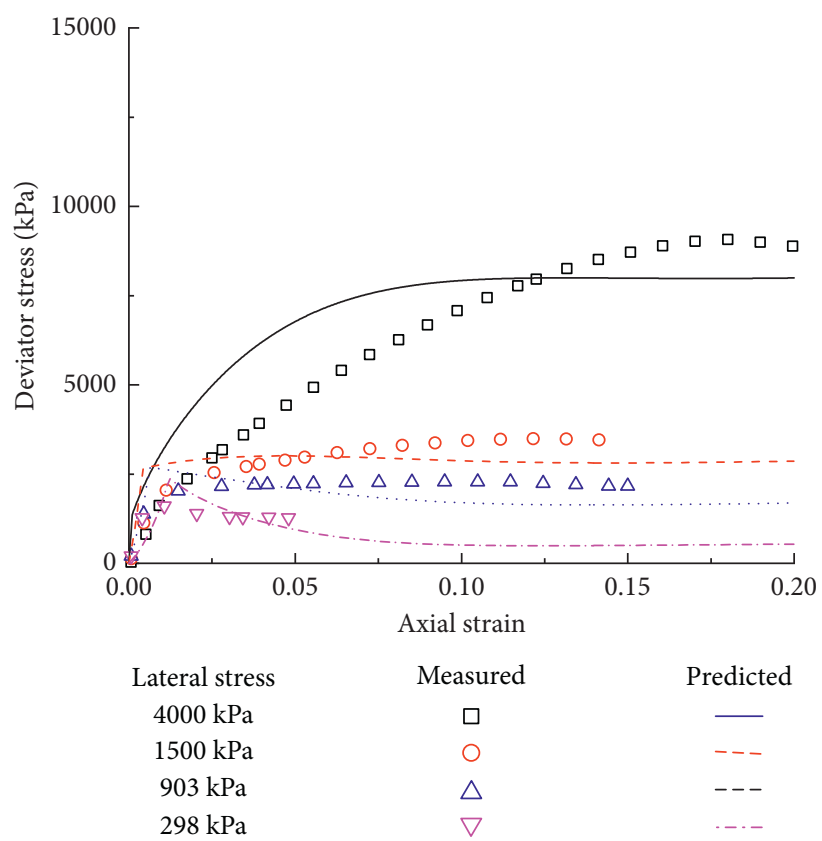

(a)

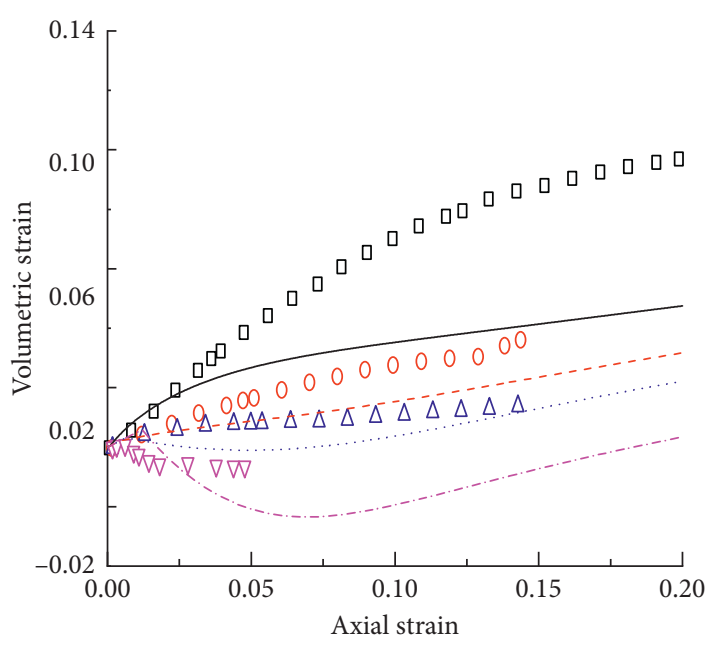

(b)

Figure 17: Comparisons of the experimental data and predictions for triaxial tests under constant confining stresses: (a) axial strain versus deviator stress; (b) axial strain versus volumetric strain.

\section{Conclusions}

Based on the mechanical behavior of structured soils, a constitutive model with subloading surface is proposed. Based upon the results, the following conclusions are drawn:

(1) The volume change of structured soils can be divided into two parts according to the new volume change correlation established in the current study. The first part is for the stress change, while the second part is for the degradation of soil structure.

(2) The structural index proposed in the current study represents the integrity of soil structure. If the structural index and the overconsolidation ratio is equal to zero, the proposed model degenerates to the modified Cam-Clay model.

(3) The influence of the soil structure and the overconsolidation are satisfactorily captured by the proposed model. The proposed model is validated through a series of experimental data obtained from the literature.

\section{Data Availability}

The data used to support the findings of this study are included within the article.

\section{Conflicts of Interest}

The authors declare that they have no conflicts of interest to report regarding the present study.

\section{Acknowledgments}

The authors appreciate the financial support of the National Natural Science Foundation of China, no. 52009049, and the Open Research Fund of State Key Laboratory of Coastal and Offshore Engineering, Dalian University of Technology, no. LP1909.

\section{References}

[1] K. H. Roscoe and J. B. Burland, "On the generalized stressstrain behaviour of wet clay," in Engineering Plasticity, pp. 535-609, Cambridge Univ, Cambridge, U.K., 1968.

[2] S. Horpibulsuk, N. Miura, and D. T. Bergado, "Undrained shear behavior of cement admixed clay at high water content," Journal of Geotechnical and Geoenvironmental Engineering, vol. 130, no. 10, pp. 1096-1105, 2004.

[3] F. Cotecchia, F. Cafaro, and B. Aresta, "Structure and mechanical response of sub-Apennine Blue Clays in relation to their geological and recent loading history," Géotechnique, vol. 57, no. 2, pp. 167-180, 2007.

[4] A. Burghignoli, S. Miliziano, and F. M. Soccodato, "Cementation effects in two lacustrine clayey soils," Geotechnical \& Geological Engineering, vol. 28, no. 6, pp. 815-833, 2010.

[5] M. D. Liu and J. P. Carter, "Modelling the destructuring of soils during virgin compression," Géotechnique, vol. 50, no. 4, pp. 479-483, 2010.

[6] S. B. Truong, N. N. Thi, and D. N. Thanh, "An experimental study on unconfined compressive strength of soft soil-cement mixtures with or without GGBFS in the coastal area of Vietnam," Advances in Civil Engineering, vol. 2020, Article ID 7243704, 12 pages, 2020. 
[7] L. Weihua, W. Jianyun, and Z. Yongxing, "Strength characteristics of cement treated and expanded polystyrene mixed lightweight of waste soil from the construction site of a yangtze river bridge in China," Advances in Civil Engineering, vol. 2020, Article ID 3640510, 7 pages, 2020.

[8] M. D. Liu and J. P. Carter, "A structured Cam Clay model," Canadian Geotechnical Journal, vol. 39, no. 6, pp. 1313-1332, 2002.

[9] M. Rouainia and D. Muir Wood, "A kinematic hardening constitutive model for natural clays with loss of structure," Géotechnique, vol. 50, no. 2, pp. 153-164, 2000.

[10] J. Suebsuk, S. Horpibulsuk, and M. D. Liu, "Modified Structured Cam Clay: a generalised critical state model for destructured, naturally structured and artificially structured clays," Computers and Geotechnics, vol. 37, no. 7-8, pp. 956-968, 2010.

[11] B. Chowdhury, A. Haque, and B. Muhunthan, "New pressurevoid ratio relationship for structured soils in the virgin compression range," Journal of Geotechnical and Geoenvironmental Engineering, vol. 140, no. 8, Article ID 06014009, 2014.

[12] W.-h. Liu, W.-g. Li, and X.-l. Sun, "New approach to interpret the mechanical behavior of structured soils," International Journal of Geomechanics, vol. 21, no. 2, Article ID 06020040, 2021.

[13] J. B. Burland, "On the compressibility and shear strength of natural clays," Géotechnique, vol. 40, no. 3, pp. 329-378, 1990.

[14] Y.-P. Yao, W. Hou, and A.-N. Zhou, "UH model: threedimensional unified hardening model for overconsolidated clays," Géotechnique, vol. 59, no. 5, pp. 451-469, 2009.

[15] J. Suebsuk, S. Horpibulsuk, and M. D. Liu, "A critical state model for overconsolidated structured clays," Computers and Geotechnics, vol. 38, no. 5, pp. 648-658, 2011.

[16] Y. Xiao, C. S. Desai, and P. E. Dist, "Constitutive modeling for overconsolidated clays based on disturbed state concept. I: Theory," International Journal of Geomechanics, vol. 19, no. 9, Article ID 04019101, 2019.

[17] Y. Xiao, C. S. Desai, and P. E. Dist, "Constitutive modeling for overconsolidated clays based on disturbed state concept. II: validation," International Journal of Geomechanics, vol. 19, no. 9, Article ID 04019102, 2019.

[18] C. S. Desai and J. Toth, "Disturbed state constitutive modeling based on stress-strain and nondestructive behavior," International Journal of Solids and Structures, vol. 33, no. 11, pp. 1619-1650, 1996.

[19] A. G. Anagnostopoulos, N. Kalteziotis, G. K. Tsiambaos, and M. Kavvadas, "Geotechnical properties of the Corinth canal marls," Geotechnical \& Geological Engineering, vol. 9, no. 1, pp. 1-26, 1991.

[20] K. Kasama, H. Ochiai, and N. Yasufuku, "On the stress-strain behaviour of lightly cemented clay based on an extended critical state concept," Soils and Foundations, vol. 40, no. 5, pp. 37-47, 2000.

[21] K. Lee, D. Chan, and K. Lam, "Constitutive model for cement treated clay in a critical state frame work," Soils and Foundations, vol. 44, no. 3, pp. 69-77, 2004.

[22] K. Hashiguchi, "Subloading surface model in unconventional plasticity," International Journal of Solids and Structures, vol. 25, no. 8, pp. 917-945, 1989.

[23] F. Zhang, B. Ye, T. Noda, M. Nakano, and K. Nakai, "Explanation of cyclic mobility of soils: approach by stress-induced anisotropy," Soils and Foundations, vol. 47, no. 4, pp. 635-648, 2007.
[24] B. Baudet and S. Stallebrass, "A constitutive model for structured clays,” Géotechnique, vol. 54, no. 4, pp. 269-278, 2004.

[25] S. Kimoto and F. Oka, "An elasto-viscoplastic model for clay considering destructuralization and consolidation analysis of unstable behavior," Soils and Foundations, vol. 45, no. 2, pp. 29-42, 2005.

[26] W. Weibull, "A statistical distribution function of wide applicability," Journal of Applied Mechanics, vol. 18, no. 3, pp. 293-297, 1951.

[27] T. Adachi, F. Oka, T. Hirata et al., "Stress-strain behavior and yielding characteristics of eastern Osaka clay," Soils and Foundations, vol. 35, no. 3, pp. 1-13, 1995.

[28] A. S. Balasubramanian and Z. M. Hwang, "Yielding of weathered Bangkok clay," Soils and Foundations, vol. 20, no. 2, pp. 1-15, 1980.

[29] P. R. Smith, R. J. Jardine, and D. W. Hight, "The yielding of Bothkennar clay," Géotechnique, vol. 42, no. 2, pp. 257-274, 1992.

[30] L. K. Walker and G. P. Raymond, "Anisotropic consolidation of Leda clay," Canadian Geotechnical Journal, vol. 6, no. 3, pp. 271-286, 1969.

[31] F. Cotecchia, The effect of the structure on the properties of and italian pleistocene clay, Ph.D. dissertation, University of London, London, England, 1996. 